\title{
Problemas para a Inserção das Tecnologias Digitais de Comunicação e Informação nas Escolas Públicas: Um Levantamento entre Professores da Grande Natal
}

\author{
Elvis Medeiros de Melo ${ }^{11}$, Rafael Moreno Ferreira ${ }^{12}$, Rodrigo Mathews de Macedo \\ Araújo $^{13}$, Isabel Dillmann Nunes ${ }^{14}$ \\ ${ }^{1}$ Instituto Metrópole Digital - Universidade Federal do Rio Grande do Norte (UFRN) \\ Av. Sen. Salgado Filho, 3000 - Lagoa Nova, CEP: 59.078-970 - Natal - RN - Brasil \\ \{elvismedeiros.mm, rafaelmf.rn, rodrigomathews7\}@gmail.com, \\ beleimd.ufrn.br
}

\begin{abstract}
Information and Communication Digital Technologies (TDIC) are increasingly present in the lives of the digital natives. The teacher training for this field is a very important subject to be taken into account. Thus, the aim in this paper discusses the insertion of TDIC into classrooms. We developed an online questionnaire and shared it with teachers and graduates, who are in contact with public schools in Grande Natal, to find out what difficulties for the insertion of technologies in schools. Quantitative analyzes of the responses, which show that about 50\% of the teachers never participated in a training course for the TDIC.
\end{abstract}

Resumo. As Tecnologias Digitais da Informação e Comunicação (TDIC) estão cada vez mais presentes na vida dos chamados nativos digitais. A formação de professores é um tema muito importante a ser levado em consideração para esse campo. Este artigo traz discussões acerca da inserção das TDIC dentro das salas de aula. Elaboramos um questionário online e compartilhamos com professores e estudantes de licenciatura, que estão em contato com escolas públicas na Grande Natal, para saber quais dificuldades para a inserção dessas tecnologias nessas escolas. Foram realizadas análises quantitativas das respostas, as quais mostram que cerca de $50 \%$ dos professores nunca participaram de curso de formação para as TDIC.

\section{Introdução}

O atual contexto educacional exige uma modificação no processo de ensino e aprendizagem. Além de dispor de Tecnologias Digitais da Informação e Comunicação (TDIC) em seu ambiente, a escola precisa integrá-las às práticas pedagógicas. Isto permitiria aos docentes dinamizar e ampliar as habilidades cognitivas de seus alunos

\footnotetext{
${ }^{1}$ Bolsista de Iniciação Científica na Universidade Federal do Rio Grande do Norte. Possui graduação em Licenciatura em Matemática. Tem experiência na área de Matemática, com ênfase em Educação Matemática, atuando principalmente nos seguintes temas: Tecnologias Digitais da Informação e Comunicação, Formação de Professores, Práticas Pedagógicas em Matemática, Objetos de Aprendizagem, Apps, Materiais Manipulativos e Programação de Jogos Educativos Digitais.

2 Aluno do Bacharelado em Tecnologia da Informação no IMD/UFRN.

${ }^{3}$ Aluno do Bacharelado em Tecnologia da Informação no IMD/UFRN.

${ }^{4}$ Possui graduação em Ciência da Computação pela Universidade Federal de Pelotas (1998), mestrado em Ciência da Computação pela Universidade Federal do Rio Grande do Sul (2001) e doutorado em Ciência da Computação pela Universidade Federal de Campina Grande (2014). Tem experiência na área de Ciência da Computação, atuando principalmente nos seguintes temas: Engenharia de Software e Informática na Educação. Atualmente é professora do Instituto Metrópole Digital da UFRN (Natal - RN).
} 
com a possibilidade de extensão da memória e de atuação em rede em razão da adoção de novos recursos educativos, nesse caso, multimidiáticos. Deste modo a escola promove a democratização do acesso a espaços e ferramentas, estimulando a vivência colaborativa, a autoria, a coautoria, a edição e a publicação de informações, mensagens, obras e produções culturais [Sousa et al 2011].

A ampliação do acesso às TDIC trouxe a possibilidade de integrá-las ao processo de ensino e aprendizagem e de implementar novas metodologias de ensino a partir dos computadores, notebooks, tablets e smartphones. As TDIC podem proporcionar desde um ambiente de interação e colaboração entre pessoas, a experiências com atividades interativas em que $o$ aprendiz explora conceitos disciplinares como os da Matemática.

Como já reforçava Valente (1999), um professor precisa de tempo para poder refletir e entender as suas escolhas pedagógicas, analisando em seguida de que forma as TDIC podem auxiliá-lo nos processos de ensino e de aprendizagem. Uma das motivações para a realização deste trabalho vem da fala de Studart (2016), quando diz que

[...] os novos tempos em educação exigirão novos professores, preparados para novas ideias e para criação de conhecimento, de forma a ser transformadores. Com o apoio das TDIC em suas aulas, a possibilidade de traçar metas e atingir marcos educacionais torna-se cada vez mais realista. Mudar o paradigma de aula tradicional a que os professores estão acostumados não parece tarefa fácil, mas necessária e gratificante.

Tomando como exemplo os cursos de licenciatura em matemática, através da pesquisa realizada por Martini e Bueno (2014), foi possível constatar que, apesar dos avanços, muitos cursos dessa licenciatura sofrem influência do paradigma tradicional, cuja ênfase ainda está na transmissão do conhecimento, por listas de exercícios e repetições. Há professores formadores que ainda não incluíram as TDIC nas suas práticas e continuam restritos às aulas expositivas e, no máximo, utilizam alguns recursos tecnológicos como assessórios para projetar exemplos mais elaborados, reproduzir vídeos ou efetuar pesquisas.

Este trabalho tem o objetivo de entender quais as dificuldades da inserção das TDIC na escola pública, a partir da análise quantitativa de respostas à um questionário. Participaram da pesquisa graduandos da licenciatura em matemática que participam de programas de iniciação à docência e de professores de pedagogia e matemática já formados, ambos que atuam/atuaram em escolas públicas da Grande Natal.

Esclarecidos a contextualização e justificativa do trabalho, apresentaremos sua estrutura. Este artigo está organizado da seguinte maneira: A seção 2 traz as discussões sobre inserção das TDIC atualmente, através da análise de fontes de um levantamento bibliográfico; a seção 3 traz a metodologia utilizada para o estudo; a sessão 4 aponta discussões e análises dos resultados de um questionário aplicado; e na seção 5 as conclusões do trabalho.

\section{TDIC e a Importância para a Escola}

As TDIC têm contribuído para uma contínua modificação na forma como nos comunicamos e construímos conhecimento. Novas ferramentas e interfaces facilitam a interação e a discussão, além de criarem possibilidades de trabalho colaborativo em tempo real, trazendo aos usuários a possibilidade de passar de consumidores passivos a criadores e coautores de conteúdos e serviços [Santana, Campos-Pinto \& Costa 2015]. 
Dentro deste contexto é importante que o currículo escolar e o planejamento docente contemplem o uso destas ferramentas, uma vez em que estão cada vez mais presentes no cotidiano de alunos e professores, sendo o seu domínio indispensável para o exercício pleno da cidadania.

Ao longo da história, a escola vem se apropriando de tecnologias para adequar recursos e metodologias às demandas sociais e para aprimorar as formas de ensinar e aprender. Nesse percurso, enfrentou e ainda enfrenta resistência de profissionais que atuam na área e que veem as inovações com ressalvas. Nas últimas décadas, por exemplo, intensificamos o debate acerca da utilização das Tecnologias Digitais de Informação e Comunicação para fins educacionais. Atualmente alguns podem imaginar que a discussão já esteja superada, uma vez que as tecnologias estão presentes nas diversas áreas do conhecimento e se tornaram um fenômeno cultural da sociedade contemporânea, não podendo a escola ignorá-las. No entanto, o que ainda se discute hoje é a forma como as TDIC devem ser apropriadas no contexto educacional, a fim de se tirar o máximo proveito do seu potencial educativo, tendo em vista que por meio delas é possível criar ambientes de aprendizagem impossíveis de serem imaginados antes de seu advento [Martini \& Bueno 2014].

As vantagens do uso das TDIC em sala de aula são muitas e é preciso considerar o aluno do século XXI, definido por Prensky (2001) como nativo digital. Este novo perfil discente possui forma diferente de produzir e se relacionar com a informação. Por serem afeitos a multimídias e com mente multitarefa, as TDIC devem fazer parte da cultura escolar dos nativos digitais. Além de respeitar o tempo e modos de interagir com o mundo do aluno, o professor precisa diversificar suas estratégias didáticas, fazendo uso de ferramentas e linguagens inerentes ao atual contexto [Almeida \& Valente 2011].

Como exemplo de TDIC, podemos citar os Objetos de Aprendizagem (OA), que segundo a definição de Wiley (2000), pode ser qualquer recurso que tenha como característica principal a reusabilidade e possa ser aberto em qualquer navegador ou instalado. Apesar de existir muitas aplicações para essa categoria de TDIC, a maioria das atividades oferecidas pelos aplicativos serve como um instrumento de aplicação e exploração ao que é dado pelo professor em sala de aula [Melo, Costa e Maia 2017]. Nessa proposta de recurso educativo digital, alinhada a abordagem instrucionista [Papert 2008], o aluno interage no sentido de exercitar o conceito por meio de atividades diretivas.

Sabe-se que muitas são as dificuldades reconhecidas no campo da matemática e, algumas delas, fazem com que os alunos desistam em meio a sua jornada. Acredita-se que, com a agregação dos Objetos de Aprendizagem (OA) ao ensino da matemática, trazem inúmeras possibilidades de sucesso nesse ramo. Tal disciplina pode ser trabalhada de forma criativa e de acordo com as dificuldades percebidas pelo professor, por meio de recursos tecnológicos [Andrade e Rodrigues 2016].

Ainda sobre a Matemática, existem contribuições muito importantes dos jogos digitais para a aprendizagem de conceitos matemáticos. Quando alinhados ao currículo oficial de Matemática, promoveram aprendizagem significativa em relação à compreensão dos registros abstratos deste componente curricular e superam a desmotivação dos alunos. Auxiliaram na melhoria dos escores obtidos nas avaliações externas e nas possibilidades de autorregulação das próprias aprendizagens dos alunos [Pereira et al 2016]. 
VI Congresso Brasileiro de Informática na Educação (CBIE 2017)

Anais dos Workshops do VI Congresso Brasileiro de Informática na Educação (WCBIE 2017)

\section{Metodologia}

Neste trabalho, analisamos as respostas de um questionário sobre a inserção das TDIC nas escolas públicas da Grande Natal, trabalho proposto em um dos módulos da disciplina Tecnologia da Informação e Sociedade, no âmbito do Instituto Metrópole Digital (IMD).

$\mathrm{Na}$ fase de planejamento do trabalho, desenhamos um mapa mental. O mapa mental, segundo Endeavor Brasil (2015), é uma espécie de diagrama que tem a função de organizar informações. Foi desenvolvido no início da década de 1970 pelo escritor e consultor em educação Tony Buzan com o intuito de ajudar as pessoas a liberar o potencial do cérebro. Consiste no seguinte sistema: Um conceito é desenhado no centro de uma página ou documento em branco; e dele são irradiadas representações de ideias por meio de imagens, palavras e partes de palavras. Todas, de alguma forma, são relacionadas ao conceito central.

Para construção do mapa, usamos a ferramenta Coggle $e^{5}$. Nesse mapa, listamos os problemas para a Inserção das TDIC, através de uma sessão de brainstorming. Focaríamos inicialmente apenas nas Tecnologias Digitais de Informação e Comunicação (TDIC), pois abrangem muito mais corpo quando falamos de tecnologias presentes e disponíveis para a prática e uso em sala de aula na escola pública.

A Figura 1 mostra o Mapa Mental elaborado no planejamento da pesquisa.

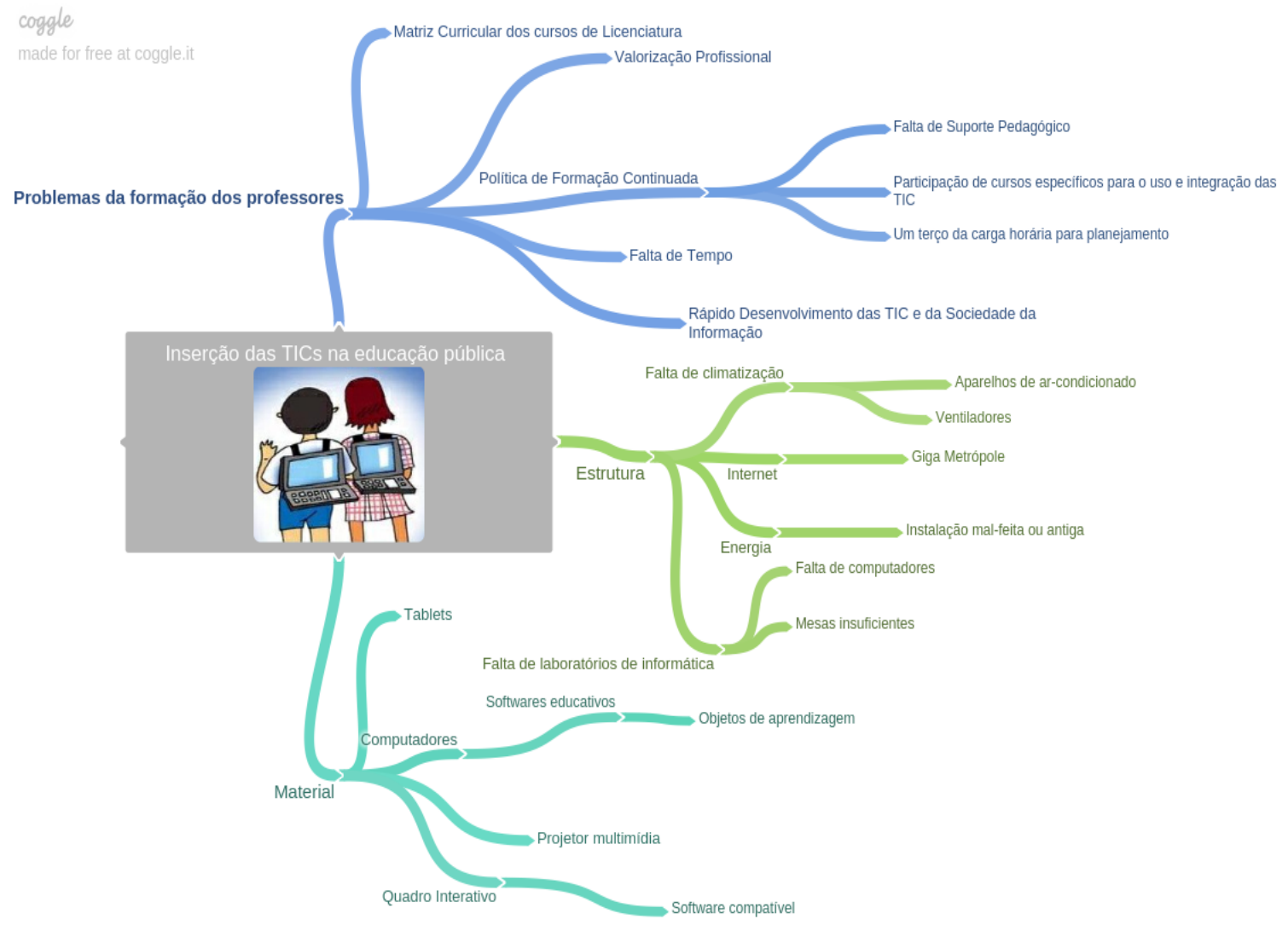

Figura 1. Mapa Mental elaborado durante a fase de Planejamento.

\footnotetext{
${ }^{5}$ https://coggle.it/. Último acesso em: 10/06/2017.
} 
Nosso público-alvo, como já mencionado, foram alunos da graduação em matemática que participam de projetos de iniciação à docência, assim como professores de matemática e pedagogia já formados, ambos que atuam/atuaram em escolas públicas da Grande Natal. A princípio, planejamos apenas entrevistar professores de atuam em escolas públicas de ensino básico, porém, acreditamos que os docentes participantes de programas de iniciação à docência, também em contato com a escola pública semanalmente, poderiam contribuir para a nossa análise quantitativa.

Optamos pelo questionário com perguntas fechadas, pois permitem análises básicas de estatística descritiva através de planilhas eletrônicas e um formulário sem a presença física do entrevistador. Questionário é um formulário impresso ou online com perguntas que os participantes da pesquisa devem responder, alcançando um grande número de pessoas dispersas geograficamente [Sanchez 1999].

As perguntas foram divididas em dois grandes blocos: Informações gerais sobre as escolas e perguntas sobre a Estrutura da escola onde esses professores atuaram/atuam. No bloco de informações gerais, fizemos as perguntas: 1. Você já teve alguma experiência dentro de sala de aula? 2. Você já usou as TDICS como recurso em sua aula? 3. Durante o curso de graduação, teve/terá alguma formação específica para o uso das TDICS? 4. Quais problemas você consideraria importantes para o uso das TDICS? 5. Já participou de algum curso de formação para as TDICS? 5.1. Se "não", poderia nos dizer qual o motivo. No bloco de perguntas sobre a estrutura da escola, levantamos, durante a construção do Mapa Mental, alguns dos possíveis problemas para a inserção das TDIC na escola pública. Usamos as sugestões como opções para os professores marcar dentro do formulário, mas deixamos um campo com a opção "Outro", caso algum problema não tenha sido levantado durante o planejamento e o professor desejasse acrescentar algo à sua resposta.

Os problemas levantados para a o bloco de perguntas sobre estrutura foram: laboratório de informática, rede banda larga sem fio, ambientes climatizados, instalação elétrica bem feita. Também levantamos questões sobre os recursos disponíveis nessas escolas, como: quadro interativo, computadores, projetor multimídia/DataShow e tablets.

\section{Resultados e Discussões}

O questionário foi disponibilizado de forma online em grupos do Whatsapp de professores de matemática e pedagogia de escolas públicas da Grande Natal e bolsistas do Programa Institucional de Bolsas de Iniciação à Docência (PIBID-Matemática), atingindo um total de trinta respostas durante os dias quatro de junho até o dia sete de junho de dois mil e dezessete, período em que o questionário ficou aberto. Do montante de respostas ao questionário, dezoito eram professores de escolas públicas da Grande Natal e doze eram bolsistas do PIBID de Matemática.

Investigamos respostas às perguntas 1 . Você já teve alguma experiência dentro de sala de aula?, e 2. Você já usou as TDICS como recurso em sua aula?. Devido ao público-alvo ter sido selecionado previamente, todos os candidatos responderam assertivamente à pergunta 1 , levando em consideração o termo "experiência" como o já desenvolvimento de alguma prática dentro de salas de aula, consequentemente o conhecimento da realidade da escola. Vejamos o percentual de respostas da pergunta 2 no Gráfico 1. 


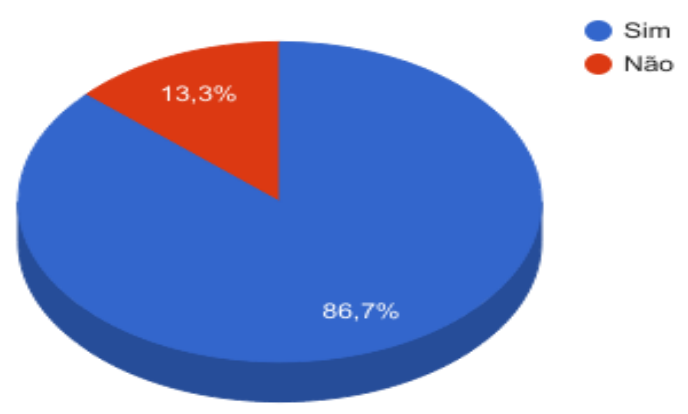

\section{Gráfico 1. Percentual de respostas à pergunta 2 do questionário.}

Com a análise do gráfico, notamos que cerca de $15 \%$ dos professores ainda não usaram as TDIC dentro de sala de aula. Isso mostra que, apesar desses recursos estarem presente no cotidiano dos alunos [Castro-Filho et al 2016], os professores ainda não utilizaram, em sua totalidade, nas suas aulas. Apesar da porcentagem baixa em relação aos professores que não usam, notamos um avanço de práticas envolvendo esse tipo de recurso dentro das salas de aula.

Sobre as respostas à questão 3. Durante o curso de graduação, teve/terá alguma formação específica para o uso das TDICS?, encontramos os percentuais presentes no Gráfico 2.

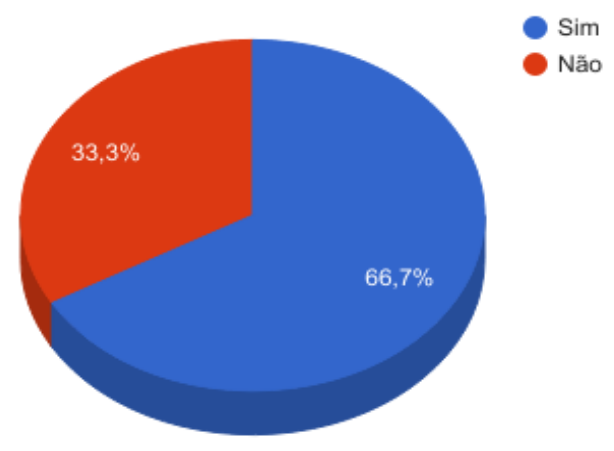

\section{Gráfico 2. Percentual de respostas à pergunta 3 do questionário.}

Observamos que, aproximadamente $35 \%$ dos entrevistados não terão/tiveram alguma formação para o uso das TDIC. É um avanço nas políticas de inserção de estudos sobre as TDIC no âmbito escolar, porém ainda existe uma parcela muito grande do professorado que não teve formação para usá-las. Sobre a pergunta 4, as respostas estão detalhadas no Gráfico 3.

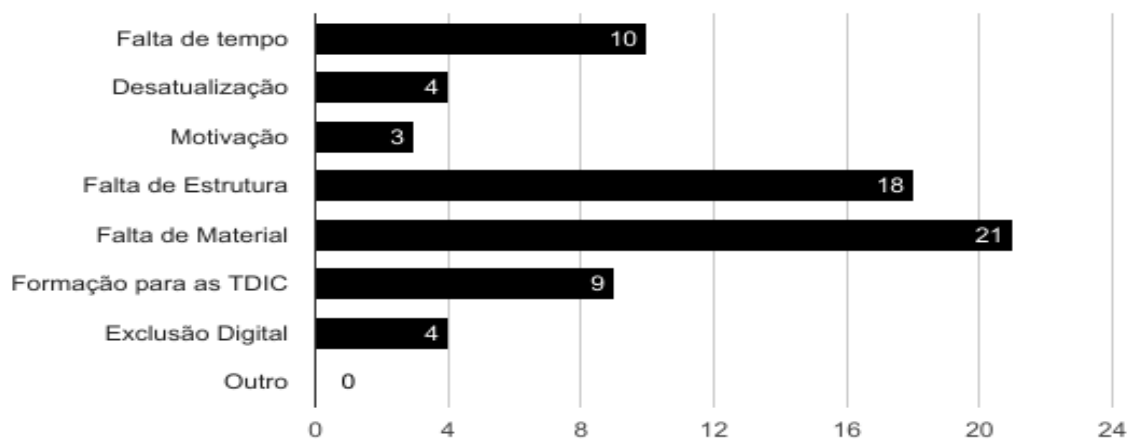

Gráfico 3. Respostas à pergunta 4 do questionário, considerando que cada pessoa pode escolher mais de um item. 
Verificamos que $60 \%$ dos professores elencaram a falta de estrutura como um dos principais problemas para a inserção das TDIC em suas aulas, assim como 70\% disseram que a falta de material necessário para as práticas está entre os problemas mais importantes. Aproximadamente $34 \%$ dos entrevistados disseram que a falta de tempo é um problema a ser considerado para o uso das TDIC.

Uma parcela mínima de $10 \%$ dos entrevistados disse que não se sentem motivados, sendo o motivo menos ocorrente durante as respostas dos professores à essa pergunta. Dos professores que responderam que a motivação era um fator determinante para a inserção das TDIC em suas práticas, observamos que os motivos estão entre: Falta de tempo, de material, de estrutura e falta de formação para as TDIC.

Vale a pena ressaltar que aproximadamente $14 \%$ dos entrevistados disseram que a Exclusão Digital, assim como a desatualização para a informática, são problemas para a inserção das TDIC na sala de aula. Isso mostra que uma parcela desses professores ainda se sente excluídos dos processos de informatização. Segundo Prensky (2008), levando em consideração as transformações da sociedade atual, com a evolução da tecnologia e educação, o desafio dos educadores é adequar seus planos de aula às necessidades da chamada de nativos digitais. Buscar esse conhecimento será fundamental.

Vejamos, a seguir, a resposta dos professores à pergunta 5. Já participou de algum curso de formação para as TDICS? E à pergunta encadeada 5.1. Se "não", poderia nos dizer qual o motivo? Através da análise do Gráfico 4.

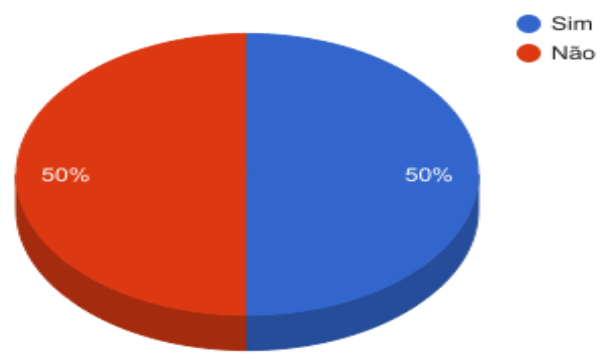

Gráfico 4. Percentual de respostas à pergunta 5 do questionário.

Ao analisar as respostas desses professores quanto à pergunta 5 , metade nunca participou de um curso de formação para as TDIC. Ao levantarmos os motivos, esses professores registraram em suas respostas: Falta de oportunidade, Falta de tempo, Não sabe onde encontrar um curso para as TDIC e Não foi oferecido pela prefeitura. Observamos que se trata de um campo amplo e que não há tanto investimento, de cursos destinados à esses professores, cursos esses que podem ser realizados durante o horário de planejamento ( $1 / 3$ da carga-horária) assegurado por lei.

Partindo para o bloco de perguntas sobre a estrutura, assim como os recursos disponíveis para as práticas de TDIC dentro da escola, observemos as respostas dos professores presentes nos Gráficos 5 e 6, respectivamente. 
VI Congresso Brasileiro de Informática na Educação (CBIE 2017)

Anais dos Workshops do VI Congresso Brasileiro de Informática na Educação (WCBIE 2017)

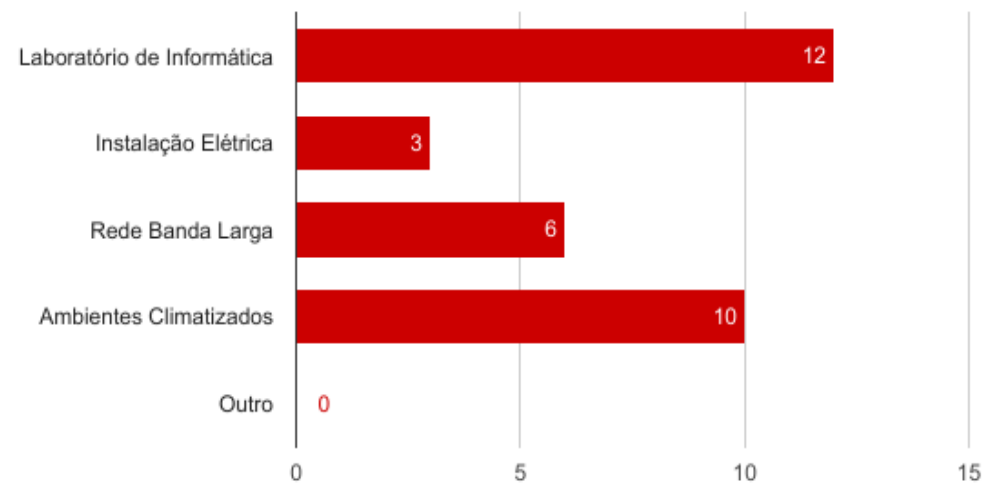

\section{Gráfico 5. Respostas à pergunta sobre estrutura da escola do questionário, considerando que cada pessoa pode escolher mais de um item.}

Aqui, dos trinta professores entrevistados, verificamos que $40 \%$ deles disseram que em suas escolas têm laboratório de informática, aproximadamente $34 \%$ responderam que em suas escolas possuem ambientes climatizados, porém, apenas $10 \%$ possuem instalação elétrica bem feita. Aproximadamente $20 \%$ das unidades de ensino possuem rede banda larga sem fio. Isso nos mostra que, apesar de algumas escolas possuírem estrutura, muito desses ambientes não são adequados para o funcionamento, por exemplo, de um laboratório de informática, ou problemas com a baixa conectividade com a internet na escola.

Já existem soluções para esse de conectividade especificamente. Como exemplo, podemos citar a Rede Giga Metrópole. A Rede Giga Metrópole ${ }^{6}$ foi desenvolvida a partir de um estudo realizado no ano de 2012, pelo Instituto Metrópole Digital (IMD/UFRN) em parceria com o PoP-RN (Ponto de Presença da Rede Nacional de Pesquisa em nosso estado), sobre a situação de conectividade com a Internet das escolas públicas da região metropolitana de Natal. A solução definida para o projeto desta rede metropolitana consiste em uma rede híbrida com a utilização de cabeamento de fibras ópticas e de rede sem fio. Numa segunda fase, a rede sem fio deverá atualizar e também ampliar o escopo da Rede Metrópole Digital, instalando novos pontos de acesso nas escolas públicas que não foram atendidas pela rede óptica.

Sobre os recursos citados no questionário, vejamos as respostas dos professores no Gráfico 6.

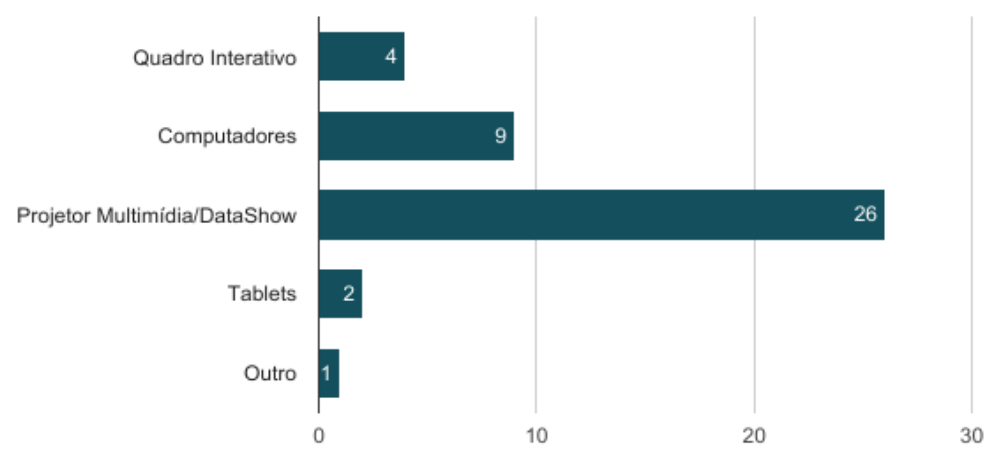

Gráfico 6. Respostas à pergunta sobre recursos disponíveis na escola do questionário, considerando que cada pessoa pode escolher mais de um item.

${ }^{6}$ https://portal.imd.ufrn.br/projetos/. Último acesso em: 10/06/2017. 
Explorando as informações do gráfico, temos que 7\% dos professores alegaram que em suas escolas possuem tablets, assim como 4\% disseram que em suas escolas possuíam outros tipos de recurso. Aproximadamente $87 \%$ das escolas desses professores possuem projetor multimídia, sendo o recurso mais citado, seguido dos computadores, onde $30 \%$ das escolas possuem. Cerca de $14 \%$ das escolas possuem quadro interativo. Fica evidente que ainda é pequeno o processo de inclusão digital nas escolas da Grande Natal.

Iniciativas são necessárias, como por exemplo, o Projeto de Inclusão Digital ${ }^{7}$ (PID) no âmbito da Universidade Regional do Noroeste do Estado do Rio Grande do Sul (Unijuí-RS) que tem o objetivo de promover a inclusão social de populações excluídas digitalmente, utilizando as tecnologias da informação como instrumento de construção e exercício da cidadania, onde seu público. Voltando para a realidade das cidades da Grande Natal, temos o Programa Nacional de Tecnologia Educacional ${ }^{8}$ (Proinfo) do Fundo Nacional de Desenvolvimento da Educação (FNDE). Esse programa está presente em algumas escolas públicas, através de cursos de capacitação oferecidos pelas Secretarias de Educação Estaduais e Municipais dos municípios da região, que tem a finalidade de promover o uso da tecnologia como ferramenta de enriquecimento pedagógico no ensino público fundamental e médio.

\section{Conclusões}

Essa pesquisa dá margem à outras investigações, como por exemplo, como nessas escolas esses equipamentos estão sendo utilizados (ou não), assim como a influência dessas práticas com TDIC na vida dos alunos.

$\mathrm{O}$ fato de realizar o questionário realmente foi satisfatório no que diz respeito à análise dos dados, visto que muitos professores dispõem de pouco tempo para a planejamento, e realizar uma pesquisa dessa natureza, presencialmente, seria bastante complicado.

Apesar de levantarmos os problemas considerados mais importantes na formação desses professores para as TDIC, como aponta o trabalho de [Alves et al. 2012], uma boa formação dos professores não é suficiente para garantir o uso das tecnologias nas escolas. O processo da inclusão digital de professores, gestores e estudantes, precisa ser analisado e discutido como um problema da comunidade escolar, considerando as particularidades e necessidades de cada grupo que compõe essa comunidade.

\section{Referências}

Alves, R.S. et al. (2012). "A utilização das TIC no ensino das escolas públicas: refletindo sobre fatores que influenciam seu uso", In: II Congresso Internacional TIC na Educação. Lisboa: Portugal. Anais.. pp. 2600-2610.

Andrade, G.O. ; Rodrigues, C.K. (2016). “Objetos de Aprendizagem na Educação Estatística: "Vem Aprender"', In: V Congresso Brasileiro de Informática na

\footnotetext{
${ }^{7}$ http://www2.unijui.edu.br/ incdigital/index.php. Último acesso em: 10/06/17.

8 http://www.fnde.gov.br/programas/programa-nacional-de-tecnologia-educacional-proinfo. Último acesso em: 10/06/17.
} 
VI Congresso Brasileiro de Informática na Educação (CBIE 2017)

Anais dos Workshops do VI Congresso Brasileiro de Informática na Educação (WCBIE 2017)

Educação (CBIE 2016), Uberlândia/MG. Anais dos Workshops do V Congresso Brasileiro de Informática na Educação (CBIE 2016).

Castro-Filho, J. A.; Maia, D. L.; Castro, J. B. de; Barreto, A. L. de O.; Freire, R. S. (2016). "Das tabuletas aos tablets: tecnologias e aprendizagem da Matemática". In: Castro-Filho, J. A. et al. (Orgs.). Matemática, Cultura e Tecnologia: perspectivas internacionais. Curitiba: CRV, p.13-34.

Endeavor Brasil (2017) "Mapa mental: arrume a bagunça no seu projeto." https://endeavor.org.br/mapa-mental/, julho de 2017.

Martini, C.M.; Bueno, J.L.P. (2014) "The challenge of information and communication technologies in initial training of mathematics teachers.”, In: Educ. Matem. Pesq., São Paulo, v.16, n.2, pp. 385-406.

Melo, E.M.; Costa, C.J.N.; Maia, D. L. (2017). "Recursos educativos digitais para Educação Matemática: um levantamento para dispositivos móveis", In: Congresso sobre Tecnologias na Educação (Ctrl+E), Mamanguape/PB. Anais do Ctrl+E 2017.

Papert, S. (2008)“A máquina das crianças: repensando a escola na Era da Informática”. ed. rev. Porto Alegre: Artmed.

Pereira et al (2016). "Jogos Digitais no desenvolvimento de conceitos matemáticos sob perspectiva BYOD e abordagem m-Learning na escola pública”, In: V Congresso Brasileiro de Informática na Educação (CBIE 2016), Uberlândia/MG. Anais dos Workshops do V Congresso Brasileiro de Informática na Educação (CBIE 2016).

Prensky, M. (2001). "Digital natives, digital immigrants”. MCB University Press, vol.9, n.5, october.

Sanchez, Sandra.(2017) "Instrumentos da pesquisa quantitativa". $\mathrm{ftp} / / / \mathrm{ftp}$.unilins.edu.br/vorlei/etec/II_mkt_EMCM/aulas/Instrumentos\%20da\%20Pesq uisa\%20Qualitativa.ppt, julho de 2017.

Santana, C. M. H.; Pinto, A. de C.; Costa, C. J. de S. A. (2015) "A ubiquidade das TDIC no cenário contemporâneo e as demandas de novos letramentos e competências na EAD." http://aunirede.org.br/revista/index.php/emrede/article/view/31, March.

Studart, Andréa (2016). "A atualização do professor diante das novas tecnologias." https://www.campograndenews.com.br/artigos/a-atualizacao-do-professor-diantedas-novas-tecnologias, julho de 2017.

Valente, J. A. (1999). "O computador na sociedade do conhecimento". Campinas: Unicamp/NIED, 11-18.

Wiley, D. A. (2000). "Connecting learning objects to instructional design theory: a definition, a metaphor, and a taxonomy”. Logan: Utah State University. 